\title{
PARQUES URBANOS E A PROBLEMÁTICA DOS ESPAÇOS DE LAZER NÃO IMPLANTADOS EM UBERABA-MG
}

\author{
Marcos Antônio Silvestre Gomes \\ Professor Associado - Universidade Federal do Triângulo Mineiro, Departamento de Geografia \\ Uberaba, MG, Brasil \\ marcos.antonio.gomes@uftm.edu.br
}

\begin{abstract}
RESUMO
Parques são áreas públicas de responsabilidade municipal com importantes funções ambientais, sociais e econômicas nas áreas urbanas. Neste artigo, procura-se avançar na compreensão destes espaços, problematizando-os no contexto da dinâmica socioespacial urbana de Uberaba-MG. São apresentados a espacialização dos parques na área urbana, relacionando a dados de renda e domicílio alugado; explicitados aspectos das políticas públicas e gestões governamentais quanto às intervenções nos parques já implantados e, ainda; demonstrado o estado geral daqueles não implantados. O trabalho fundamentou-se em pesquisas bibliográficas, consultas em sítios na internet, análise da legislação municipal, levantamentos de dados em secretarias municipais, observações de campo nos parques e entrevistas com a população. Constatou-se que os parques já implantados estão mais centralizados na área urbana e agrava diversos problemas que comprometem seus usos. Por outro lado, nas áreas periféricas há significativos espaços públicos demarcados com a intenção de se transformarem em parques, mas que se encontram abandonados, sem infraestrutura e, por vezes, negligenciados por diversos agentes sociais. Mais da metade das áreas designadas parques em Uberaba não se encontra definitivamente implantada, são existentes somente no papel, constituindo vazios urbanos ociosos no espaço, desconhecidos da população em geral, embora representem inestimável potencial socioambiental.
\end{abstract}

Palavras-chave: Parques urbanos. Espaços públicos. Políticas públicas. Uberaba.

\section{URBAN PARKS AND THE PROBLEMS OF NOT IMPLANTED LEISURE SPACES IN UBERABA-MG}

\begin{abstract}
Parks are public spaces of local government responsibility and have important environmental, social and economic functions in the urban areas. In this article, the focus is to understand the parks in the urban sociospatial context of the city of Uberaba-MG. It presents maps of the parks in the urban area, related of income data and rented residence; explains aspects of public politics and governmental management regarding interventions in the parks implanted and even; demonstrates general condition of those not implemented. The work was based on bibliographic research, consultations in websites, analysis of city legislation, data collection in the city departments, field observations in the parks and interviews with the population. The results show that the parks implemented are more centralized in urban area and worsen several problems than compromises its uses. However, in peripheric areas there are many demarcated public spaces with the intention to be transformed in parks, but that are abandoned, without infrastructure and sometimes, denied by various social agents. More than half of the designated park area in Uberaba is not definitively implanted, exist only in paper, constituting empty urban voids in space, unknown by the general population, although they represent invaluable social-environmental potential.
\end{abstract}

Key words: Urban Parks. Public Spaces. Public Politics. Uberaba.

\section{INTRODUÇÃO}

Parques compõem as áreas urbanas como elementos relevantes na dinâmica socioespacial, desempenhando funções ambientais, sociais e econômicas que atestam a sua importância como espaços públicos. Muitos parques funcionam como "ilhas" naturais ou planejadas pela ação humana

$\begin{array}{lllll}\text { Caminhos de Geografia } \quad \text { Uberlândia-MG } & \text { v. 21, n. } 78 & \text { Dez/2020 } & \text { p. 237-252 Página } 237\end{array}$


que contribuem na regulação do equilíbrio solo-clima-vegetação, amenizando as adversidades climáticas das cidades e proporcionando formas de interação sociedade e natureza.

Apesar de haver importantes discussões quanto à definição e conceituação dos espaços públicos em sua diversidade de categorias, como praças, áreas verdes, espaços livres etc, a literatura ainda padece de uma análise profunda no que se refere às áreas denominadas parques. No âmbito do planejamento urbano, tornou-se comum esta denominação para espaços que atinjam especialmente área superior a uma ou duas quadras padrões de um loteamento, mesmo que seus conteúdos nada digam quanto ao reconhecimento pela sociedade da essência desses espaços. Este é um problema teórico-conceitual que este artigo não propõe resolução, mas caminha no sentido de evidenciar o debate quanto à pertinência desta questão para os estudos urbanos.

Para Macedo e Sakata (2003, p. 14) o parque urbano constitui "espaço de uso público destinado à recreação de massa, qualquer que seja o seu tipo, capaz de incorporar intenções de conservação cuja estrutura morfológica é autossuficiente, isto é, não é diretamente influenciada em sua configuração por nenhuma estrutura construída em seu entorno".

Por sua vez, Carneiro e Mesquita (2000, p. 20) definem o parque urbano em seu caráter livre, público e recreativo, que ocupe "uma área em grau de equivalência superior a uma quadra típica urbana, em geral apresentando componentes da paisagem natural, vegetação, topografia, elemento aquático, como também edificações destinadas a atividades recreativas, culturais e/ou administrativa."

Como se observa, em suas proposições os referidos autores ressaltam sobretudo elementos de ordem natural/ecológico e de lazer, mas também destacam o caráter público do parque. Isto aparece de forma resumida no âmbito do Ministério do Meio Ambiente1, para o qual o "parque urbano é uma área verde ${ }^{2}$ com função ecológica, estética e de lazer, no entanto, com uma extensão maior que as praças e jardins públicos". Sobre as dimensões adequadas destes espaços, nada é dito.

No âmbito deste trabalho, ressalta-se a compreensão dos parques como "espaços públicos designados por lei, oriundos do parcelamento do solo, do aproveitamento de terras públicas ou de processos de desapropriação, cujos atributos permitem cumprir funções socioambientais" (GOMES, 2019). No Brasil, parques urbanos são instituídos pelas municipalidades através da designação de áreas verdes ou institucionais, em conformidade com a Lei Federal $6766 / 79^{3}$, que dispõe das condições do parcelamento do solo urbano. Podem também resultar de processos de desapropriação de áreas privadas de interesse público.

Como nas metrópoles, em cidades de porte médio como Uberaba-MG, que este estudo analisa, parques também integram a problemática urbana e, com frequência, são justificados como componentes de melhoria da qualidade de vida e qualidade ambiental urbana. No entanto, os processos que envolvem a criação ou modernização destes espaços, em geral, obedecem a uma lógica de interesse privado, predominando projetos em áreas de maior retorno imobiliário ou áreas centrais. É nesse sentido que, por vezes, as políticas públicas, por mais que apareçam como democráticas na lei, na prática, se desdobram ampliando as desigualdades socioespaciais urbanas, características das cidades capitalistas.

Este artigo recupera análises já produzidas em outros momentos sobre os parques urbanos de Uberaba-MG, ampliando a problematização desses espaços na dinâmica espacial urbana. Apresenta a espacialização dos parques na área urbana, relacionando-a com dados de renda e domicílio alugado, destaca aspectos das políticas públicas e das gestões governamentais quanto às intervenções nos parques já implantados e demonstra o estado geral daqueles não implantados. $O$ trabalho avança no sentido de se compreender as razões pelas quais, sobretudo, as áreas periféricas detém significativos espaços públicos demarcados com intenção de se transformarem em parques, mas que amargam a realidade de conviverem com espaços abandonados, sem infraestrutura e, por vezes, negligenciados por diversos agentes sociais. Mais da metade das áreas designadas parques em Uberaba não se encontra definitivamente implantada, assim são existentes somente no papel, constituindo vazios urbanos ociosos no espaço, desconhecidos da população em geral, embora representem inestimável conteúdo ecológico.

1 Disponível: https://www.mma.gov.br/cidades-sustentaveis/areas-verdes-urbanas/item/8051.html. Acesso: setembro de 2019.

2 Conforme o Art. $8^{\circ}, \S 1^{\circ}$, da Resolução CONAMA No $369 / 2006$, área verde pública é "o espaço de domínio público que desempenhe função ecológica, paisagística e recreativa, propiciando a melhoria da qualidade estética, funcional e ambiental da cidade, sendo dotado de vegetação e espaços livres de impermeabilização".

3 Dispõe sobre o Parcelamento do Solo Urbano e dá outras Providências. Alterada pela Lei $n^{\circ}$ 9.785, de 1999.

$\begin{array}{lllll}\text { Caminhos de Geografia } & \text { Uberlândia-MG } & \text { v. 21, n.78 } & \text { Dez/2020 } & \text { p. 237-252 Página } 238\end{array}$


A metodologia do trabalho envolveu pesquisas bibliográficas sobre a temática, consultas em sítios jornalísticos da internet, análise da legislação municipal (Plano Diretor Municipal, Código Municipal do Meio Ambiente, entre outros), levantamentos de dados em secretarias municipais, observações de campo em diversos parques e entrevistas com a população. As especificações de algumas destas etapas metodológicas constam ao longo do texto.

O artigo se organiza em três partes, além da Introdução e Considerações Finais. Inicialmente aborda a problematização socioespacial dos parques, depois faz uma análise das políticas públicas e do estado geral dos parques implantados, e, por fim realiza a caracterização dos espaços não implantados e demonstra a percepção da população lindeira.

\section{PROBLEMATIZAÇÃO SOCIOESPACIAL DOS PARQUES URBANOS EM UBERABA-MG}

O município de Uberaba-MG está localizado na Região do Triângulo Mineiro/Alto Paranaíba, com população estimada em 333.783 habitantes em 2019, dos quais cerca de $98 \%$ habitam a área urbana. Sua área territorial total é de $4.523,957 \mathrm{~km}^{2}$ e o Produto Interno Bruto (PIB) em 2014 somou 11,6 bilhões de reais, destacando-se por ordem de importância econômica os setores de serviços, industrial e agropecuário. O Índice de Desenvolvimento Humano Municipal (IDHM) em 2010 foi de 0,772 e o salário médio mensal de 2,6 salários mínimos em 2017 (IBGE $\left.{ }^{4}\right)$.

Nas últimas décadas o município apresentou elevado dinamismo econômico, despontando-se como o segundo maior PIB da região e, a partir de análises de sequências históricas, Gomes (2015, p. 528529) afirma que este "vem passando por transformações na dinâmica econômica e urbana, com a atração de novos investimentos nos diferentes setores de atividades econômicas, resultando, consequentemente, no crescimento do PIB e da população".

Em específico, no espaço urbano, Uberaba apresenta indicadores positivos quanto à infraestrutura geral: 99,9\% dos imóveis tem cobertura por rede de água, 98\% são atendidos por rede coletora de esgotos, 99,97\% são abastecidos com energia elétrica e 98\% do esgoto é tratado (ANUÁRIO, 2019, p. 23). Contraditoriamente, problemas de diversas ordens também são evidentes, em especial aponta-se, conforme os propósitos deste estudo, a carência generalizada de cobertura vegetal efetiva ${ }^{5}$, excesso de áreas impermeabilizadas e ineficiência dos espaços públicos de lazer, como as praças e os próprios parques.

Conforme Guerra, et. al. (2015, p. 21), em Uberaba existem

aproximadamente 200 áreas verdes, entres praças, canteiros públicos e parques, mas que não constituem um sistema ou rede. A existência destas áreas verdes não reflete a qualidade destes espaços para o uso do lazer nem sua distinção como áreas de preservação, algumas áreas existem apenas no papel, pois de fato ou estão tomadas pelo mato, ou são sobras de um traçado urbano ditado pelo valor de terra, pelos interesses particulares de alguns agentes ou mesmo pela falta de planejamento urbano.

No caso específico das praças públicas, Gomes e Savelli (2019, p. 3167-3168) apontam que estas, em sua maioria, localizam-se nos setores censitários de maior renda e na mancha urbana mais adensada. Bairros mais pobres e conjuntos habitacionais populares, distantes da área central, como o Residencial 2000 e o bairro Beija-Flor, não dispõem de praças efetivamente implantadas. Para estes autores,

a problemática das praças é parte da problemática urbana em sua totalidade. Há um descompasso entre as políticas públicas aplicadas nas áreas periféricas de baixa renda e nas áreas centrais e imediações. Problemas envolvendo arborização, beleza cênica, manutenção, diversidade de equipamentos, iluminação e policiamento é recorrente nas praças e se tornam agudos nos bairros de baixa renda, fato que impõe a necessidade de ações efetivas do poder público, garantindo a função social da cidade e assegurando os princípios da cidadania.

Apesar dos estudos apontados, e outros, como o de Nascimento (2016), Silva (2016) e Ferreira (2015), terem destacado o conjunto de problemas que norteia os parques e praças de Uberaba, a

\footnotetext{
${ }^{4}$ Disponível: https://cidades.ibge.gov.br/ Acesso: maio/2018.

${ }^{5}$ Informações do sitio da Prefeitura Municipal, através da Secretaria Municipal de Meio Ambiente e Turismo de Uberaba (2014). 
mídia tem constantemente noticiado o problema ${ }^{6}$. Tratam-se de matérias que demonstram o estado de "abandono" dos parques, evidenciando a perenidade do problema. No entanto, como se demonstra nesta análise, a questão vai além do estado atual dos parques já implantados, mas transcorre pela não efetivação da política urbana que garante, por lei, a criação de inúmeros outros parques.

O Plano Diretor Municipal ${ }^{7}$ (Lei 359/2006), em seu artigo 106, discrimina onze áreas públicas como parques na área urbana (Quadro 1):

Quadro 1 - Uberaba-MG: Parques públicos urbanos discriminados no Plano Diretor Municipal (Lei nº 359/2006)

\begin{tabular}{ll}
\hline Nome do Parque & Localização/Bairro \\
\hline Parque Ecológico Mata do Carrinho & Parque das Américas \\
\hline Parque Mata José Elias (Parque do Paço) & Santa Marta \\
\hline Parque Municipal Mata do Ipê & Leblon \\
\hline Bosque do Jacarandá (parque e zoológico) & Jardim São Bento \\
\hline Parque Mata do Bacuri & Quinta da Boa Esperança \\
\hline Parque São Cristóvão & Paraíso \\
\hline Parque Linear Grande Horizonte & Parque Grande Horizonte, Villaggio dei Fiori, \\
Parque Córrego das Lajes & Recanto das Torres e Jardim Uberaba \\
Parque Tancredo Neves & Jardim São Bento \\
Parque no entorno do Piscinão (Parque das & Parque do Mirante \\
Acácias) & \\
\hline Parque 2000 & Residencial 2000 \\
\hline
\end{tabular}

Org - Marcos Antônio Silvestre Gomes

O Quadro 1 enumera parques em quantidade significativa para uma cidade do porte de Uberaba, os quais apresentam-se distribuídos desigualmente na área urbana e, em muitos casos, seus usos estão comprometidos, ou mesmo encontram-se como espaços abandonados, sem qualquer infraestrutura. Destes elencados, apenas os parques do Jacarandá, Mata do Ipê, Mata do Carrinho, das Acácias e do Paço encontram-se efetivamente implantados.

Apesar de muitas áreas serem denominadas parques, como analisado a posteriori, são recomendadas para criação ou implantação, conforme Artigo 107 do Plano Diretor. No entanto, o fato de constarem indicadas não garante a sua efetivação. Reflexo disso é a discussão do Parque Mata do Bacuri, localizado na Quinta da Boa Esperança, nas proximidades da área central.

Este parque (Mapa 1), discriminado no Plano Diretor (conforme Quadro 1), encontra-se numa área de 7,5 hectares prevista para desapropriação pela sua relevância ambiental e cultural. No entanto, está em discussão, na atual revisão do Plano Diretor, a revogação da área para parque a fim de ceder espaço a um loteamento, o que redundaria em perdas inestimáveis para o patrimônio público ${ }^{8}$. Ou seja, os interesses do setor imobiliário mostram-se claros e incisivos, redundando em processos judiciais para garantia da área, por pressão de segmentos da sociedade civil.

Os parques denominados por lei em Uberaba estão espacializados nos Mapas 1 e 2, que permitem uma análise acoplada a informações socioespaciais de renda e domicílios alugados. Foram ainda

6 Dentre outras matérias, aqui destacam-se duas: "Domingo sem parque”, Jornal de Uberaba, edição de 29 de julho de 2018; e "Parques de Uberaba estão entregues ao descaso". Disponível no sítio do G1 (G1.globo.com), de 18 de janeiro de 2012 .

7 No presente momento está em revisão o Plano Diretor Municipal de Uberaba, cuja minuta está em discussão na Câmara Municipal.

8 Para mais detalhes, consultar: https://medium.com/@caquiver/quinta-da-boa-esperan\%C3\%A7a-a\%C3\%BAltima-de-chance-de-um-parque-central-para-uberaba-284fc921f2bb

$\begin{array}{lllll}\text { Caminhos de Geografia } & \text { Uberlândia-MG } & \text { v. 21, n. 78 } & \text { Dez/2020 } & \text { p. 237-252 Página } 240\end{array}$


incorporadas informações de outros parques listados em documento público em forma de um mapa denominado "Àreas de Qualificação Ambiental Urbana", da Prefeitura Municipal de Uberaba, de 2015.

Mapa 1 - Uberaba-MG: Parques públicos urbanos e renda por setor censitário (2020).

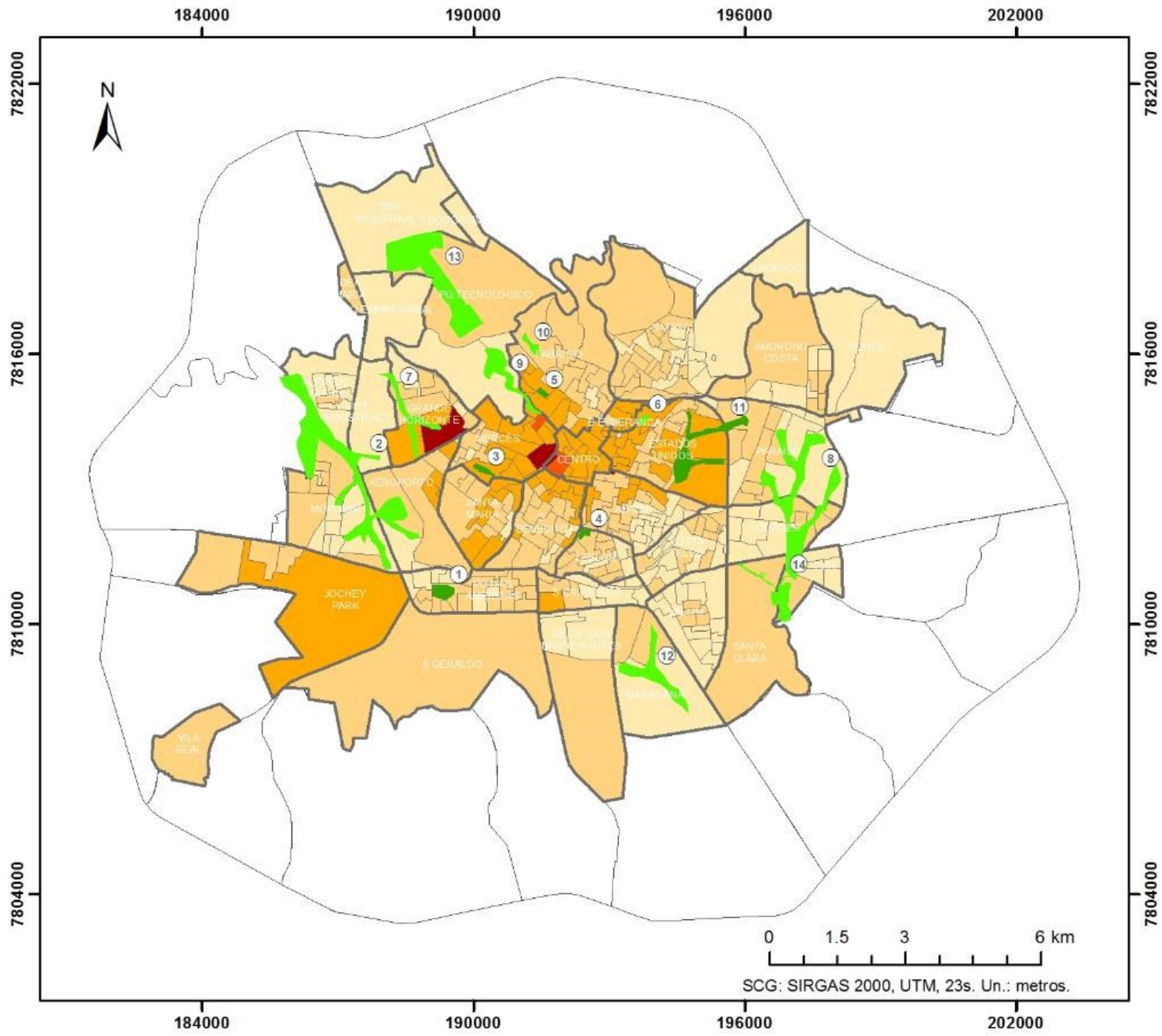

\begin{tabular}{|c|c|c|}
\hline Parques em funcionamento & Identificador & Parque \\
\hline $\begin{array}{l}\text { Parques em funcionamento } \\
\text { não }\end{array}$ & 1 & Pq Ecológico Mata do Carrinho \\
\hline \multirow{3}{*}{ salários mínimos } & 2 & Pq Linear do Córrego Jucá \\
\hline & 3 & Pq Mata do José Elias \\
\hline & 4 & Mata do Ipê \\
\hline & 5 & Bosque do Jacarandá \\
\hline \multirow[t]{2}{*}{2 a 4} & 6 & Pq Mata do Bacuri \\
\hline & 7 & Pq Linear Novo Horizonte \\
\hline 4 a 10 & 8 & Pq São Cristóvão \\
\hline 10 a 15 & 9 & Pq Córrego das Lajes \\
\hline acima de 15 & 10 & Pq Tancredo Neves \\
\hline \multirow{5}{*}{$\begin{array}{l}\text { Sem dados } \\
\text { Subdistritos }\end{array}$} & 11 & Pq Cabeceira Cór. Lajes e Entorno do Piscinão \\
\hline & 12 & Mata Nasc. Córrego Sucuri \\
\hline & 13 & Pq Tecnológico \\
\hline & 14 & $\mathrm{Pq} 2000$ \\
\hline & \multicolumn{2}{|c|}{$\begin{array}{l}\text { Fonte: } \\
\text { - Parques Urbanos (PMU, 2015) } \\
\text { - Renda média chefe de familia por setor censitário (IBGE,2010) }\end{array}$} \\
\hline
\end{tabular}

Autor - Ricardo Vicente Ferreira; Org. Marcos Antônio Silvestre Gomes. 
Mapa 2 - Uberaba-MG: Parques públicos urbanos e domicílios alugados por setor censitário (2020).

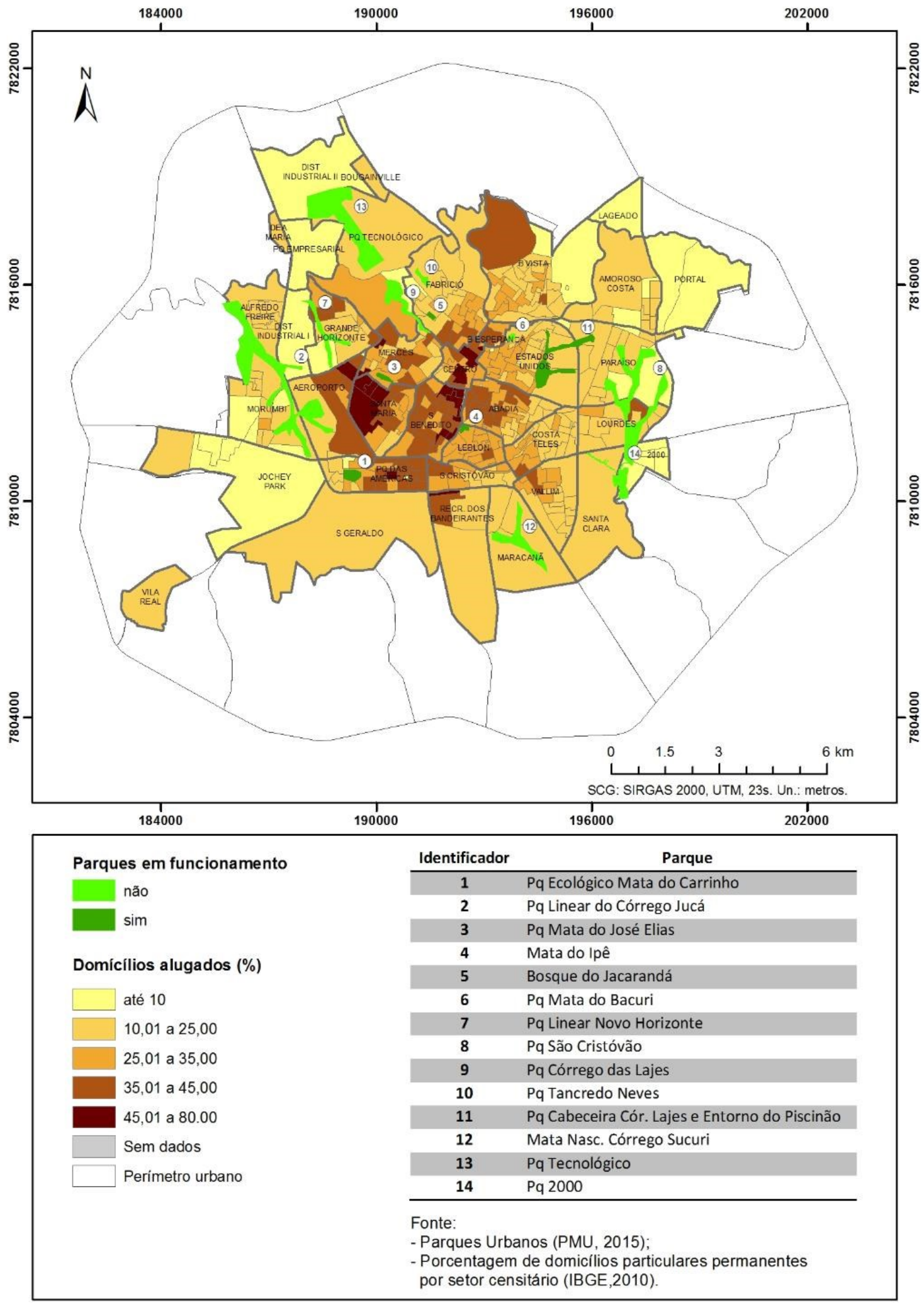

Autor - Ricardo Vicente Ferreira; Org. Marcos Antônio Silvestre Gomes.

Neste texto serão utilizadas as seguintes nomenclaturas para tratar de alguns parques retratados nos 
mapas: Parque das Barrigudas para se referir ao Parque Tecnológico ${ }^{9}$, tendo em vista que ocupa pequena parte desta área territorial maior, Parque das Acácias para se referir ao Parque Cabeceira Córrego das Lages e Entorno do Piscinão, e Parque do Paço, para tratar do Parque Mata José Elias. A escolha destas nomenclaturas se justifica pela forma que são divulgados oficialmente pelo poder público, quer seja através de placas nos locais ou leis específicas de criação dos mesmos.

Os mapas sinalizam a condição socioeconômica dos bairros onde existem parques implantados e não implantados. Demonstram os fatores renda e domicílios alugados, permitindo uma leitura mais aprofundada sobre a realidade urbana.

No que se refere ao primeiro fator, evidencia-se, no Mapa 1, que os parques implantados estão localizados na área urbana mais adensada, em geral, com predominância de rendas elevadas. Os parques não implantados encontram-se na franja urbana, onde a renda apresenta-se mais baixa.

Quanto ao fator domicílios alugados (Mapa 2), duas áreas se destacam, uma que compreende o aeroporto e bairro Santa Maria, incluindo bairros Olinda e Universitário, e outra, englobando a região do Centro e do bairro Abadia. Tradicionalmente há uma procura maior por imóveis nestas localidades em função do número de estudantes nas universidades públicas e privadas instaladas nas mesmas. Porém, os parques nas suas proximidades não se apresentam favoráveis a uso efetivo. A reforma na Praça Pôr do Sol no bairro Olinda e a finalização da revitalização do Parque Mata do Carrinho significam avanços importantes para o lazer nas imediações do bairro Universitário, mas também um projeto de ampliação e revitalização da Mata do Ipê seria fundamental para o público da Abadia.

Os parques urbanos efetivamente implantados em Uberaba foram criados em períodos distintos e os mais recentes, como Parque das Acácias e Parque do Paço, encontram-se mais centralizados na malha urbana, sinalizando a prioridade do poder público em áreas de maior interesse imobiliário (Figuras 1 e 2). Outros parques, quando foram criados nas décadas de 1960 a 1980 (Mata do Carrinho, Mata do Ipê e Jacarandá) ${ }^{10}$, localizavam-se basicamente na franja urbana, embora atualmente encontram-se em um raio de até 4 quilômetros da área central (Figuras 3 e 4).

Os parques implantados no período de 1960 a 1980 se caracterizam, predominantemente, pela presença de vegetação densa, em geral, com espécies arbóreas nativas de grande porte, como os parques do Jacarandá, Mata do Ipê e Mata do Carrinho ${ }^{11}$, com fins predominantes de lazer contemplativo. No entanto, alguns parques criados por lei a partir da década de 2000 apresentam-se como espaços de cobertura vegetal exótica, esparsa, prestando-se, sobretudo, ao embelezamento paisagístico e ao lazer ativo.

Figura 1 - Uberaba (MG): Parque das Acácias (2018).

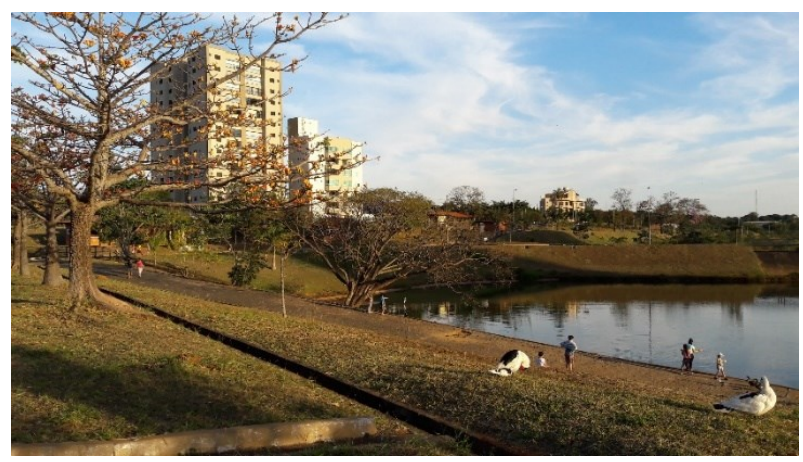

Autor - Marcos Antônio Silvestre Gomes.

9 Área que reúne um complexo empresarial e de instituições de pesquisas. Mais informações em: http://www.parquetecnologicouberaba.com.br.

10 De acordo com a Lei 6599/1998, o "Bosque Jacarandá, criado pela Lei Municipal n 1423, de 16 de Fevereiro de 1.966, passa a denominar-se PARQUE MUNICIPAL DO JACARANDÁ, situado no Loteamento Vila Olímpica, com $32.812 \mathrm{~m}^{2}$, de área de preservação ambiental". A "Mata do Carrinho, considerada de preservação permanente pelo Decreto $n^{\circ} 381$, de 04 de Junho de 1.985, passa a denominar-se PARQUE MUNICIPAL DA MATA DO CARRINHO, situado no Bairro Parque das Américas, com $132.567,00 \mathrm{~m}^{2}$, de área de preservação ambiental". E a "Mata do Ipê, criada pela Lei Municipal n².593, de 20 de abril de 1976, passa a denominar-se PARQUE MUNICIPAL MATA DO IPÊ, situado no Bairro Parque São Geraldo, com $35.301,00$ m² $^{2}$, de preservação de área ambiental".

11 Estudo sobre a vegetação nestes parques foi desenvolvido por Pegorari (2007), que realizou o levantamento, descrição e análise das espécies arbóreas em fragmentos de vegetação nestes espaços.

$\begin{array}{lllll}\text { Caminhos de Geografia } & \text { Uberlândia-MG } & \text { v. 21, n. 78 } & \text { Dez/2020 } & \text { p. 237-252 Página } 243\end{array}$


Figura 2 - Uberaba (MG): Parque do Paço (2020).

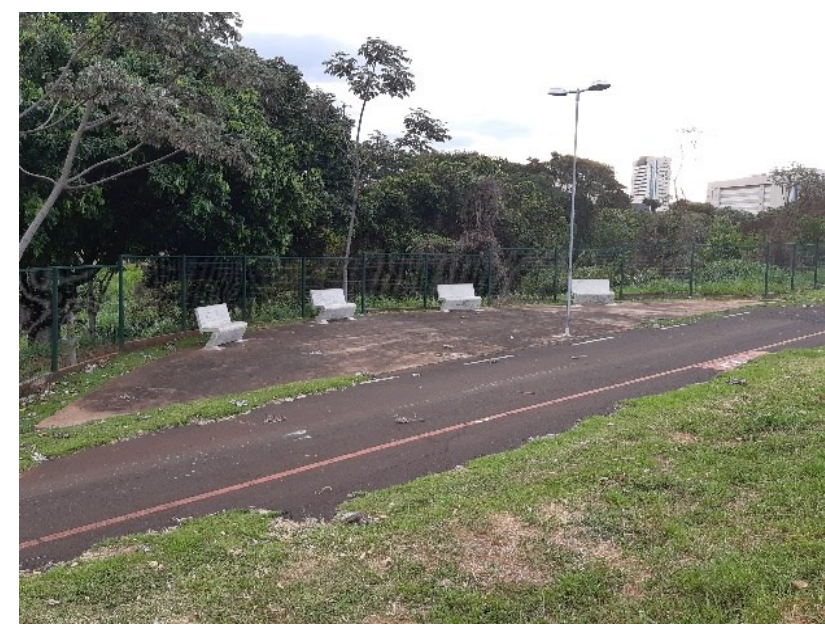

Autor - Marcos Antônio Silvestre Gomes.

Figura 3 - Uberaba (MG): Parque Mata do Carrinho (2017).

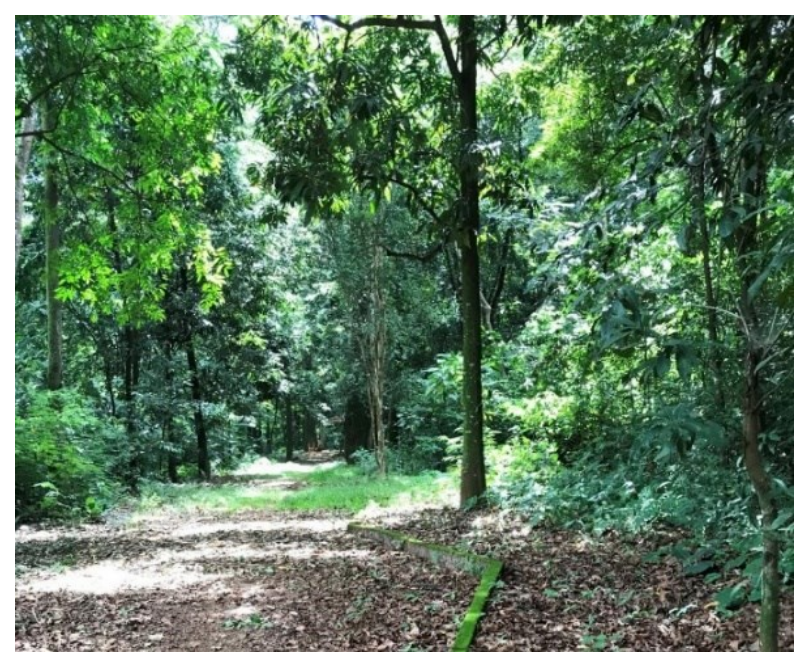

Autor - Stella Márcia Pereira.

Figura 4 - Uberaba (MG): Parque Jacarandá, em primeiro plano (data aproximada: 2014; Ao centro, estruturas do Praça Uberaba Shopping; à direita, área destinada à criação do Parque Córrego das Lages).

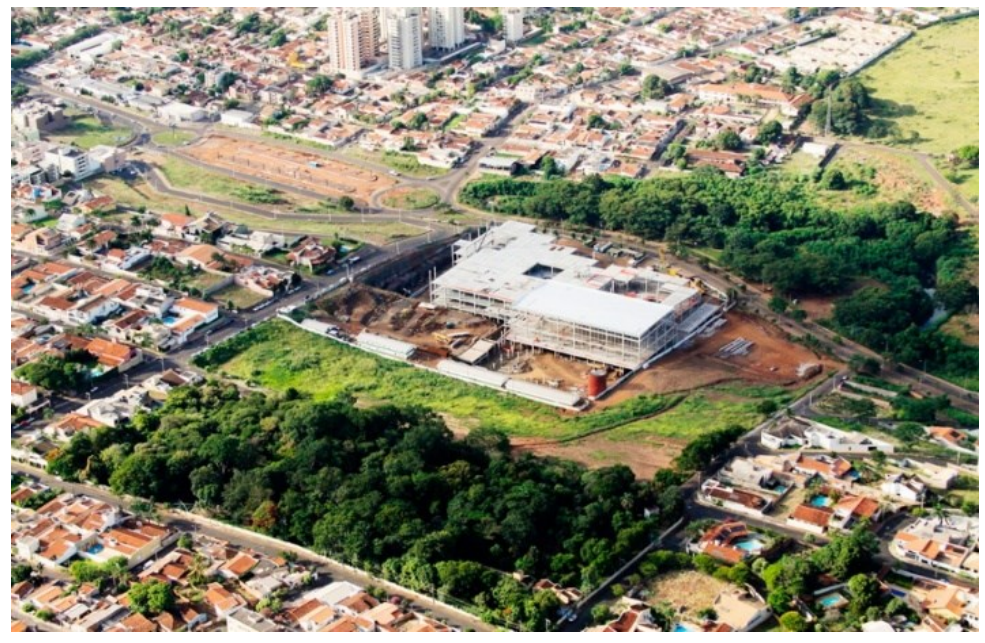

Fonte - http://www.pracauberabashopping.com.br. Acesso: janeiro de 2015. 
Figura 5 - Uberaba (MG): Parque das Barrigudas (2018).

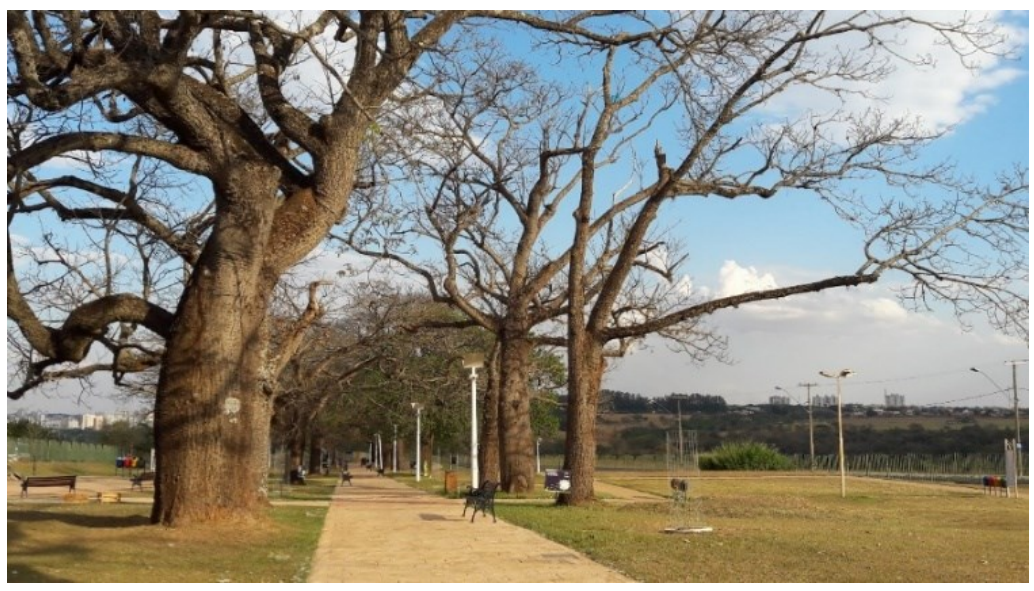

Autor - Marcos Antônio Silvestre Gomes.

O Plano Diretor de Uberaba destaca dezenas de espaços públicos para fins de "qualificação ambiental e revitalização12", a exemplo de muitos parques constantes no Quadro 1. No entanto, inúmeros parques não foram criados por lei específica e apenas algumas intervenções pontuais foram realizadas na última década em parques oficialmente criados. Nestas condições, observa-se a necessidade de reconhecer os avanços das políticas municipais na criação e gestão de parques na cidade.

\section{AS POLÍTICAS PÚBLICAS E O ESTADO GERAL DOS PARQUES IMPLANTADOS}

Para compreender as políticas públicas referentes aos parques foi necessário conhecer a legislação municipal vigente e sua efetiva aplicabilidade pelo poder executivo local. Em Uberaba, há um conjunto de leis que trata dos parques, sendo as mais abrangentes, consultadas para este trabalho: Lei do Parcelamento do Solo Urbano (Lei Complementar N. ${ }^{\circ} 375 / 2007$ ), Lei de Uso e Ocupação do Solo (Lei Complementar N. ${ }^{\circ}$ 376/2007), Plano Diretor Municipal (Lei Complementar N. ${ }^{\circ}$ 359/2006), Código do Meio Ambiente (Lei Complementar N. ${ }^{\circ}$ 389/2008) e Lei Orgânica Municipal (N. ${ }^{\circ}$ 65/1990).

Ao reconhecerem os parques como elementos fundamentais do patrimônio natural e da paisagem urbana, as leis evidenciam, de um lado, a importância do acervo ou conteúdo natural dos mesmos, como nascentes, espécies nativas da flora e fauna, sobretudo, avifauna; de outro, a condição estética e benefícios ambientais à saúde humana que proporcionam. Em suma, ressaltam-se a importância não apenas de melhorar os aspectos naturais e estruturais dos parques existentes como destacado a posteriori, mas de criar por lei e efetivar outras áreas para compor o sistema de parques, ampliando as vantagens socioambientais destes espaços.

O Plano Diretor de Uberaba (Artigo 107, grifos nossos) aponta a necessidade de criar e implantar unidades de conservação e áreas de lazer e discriminadamente os seguintes parques:

$[\ldots]$

II - criação de um parque na área de lazer na Mata José Elias;

III - implantação do Parque Mata do Bacuri, para preservação de espécies vegetais remanescentes do cerrado, com a desapropriação ou aquisição da área de propriedade particular, através dos instrumentos da política urbana;

IV - implementação de parque no Bosque do Jacarandá com a regularização das áreas particulares no seu interior, identificação do perfil do visitante, adequações necessárias para o funcionamento do zoológico e implantação de infra-estrutura para visitação pública;

V - implementação do Parque Linear Grande Horizonte, buscando parcerias com as empresas instaladas no Distrito Industrial I, para a preservação e manutenção da área, como medida compensatória ou atenuante de impacto ambiental, de acordo com a legislação ambiental vigente;

\footnotetext{
12 Termos utilizados na lei, mas que se embutem de uma complexa compreensão na literatura.
}

$\begin{array}{lllll}\text { Caminhos de Geografia } & \text { Uberlândia-MG } & \text { v. 21, n. } 78 & \text { Dez/2020 } & \text { p. 237-252 Página } 245\end{array}$


VI - criação do Parque Linear São Cristóvão como contrapartida da construção do aterro sanitário municipal;

VII - criação do Parque Linear Córrego das Lages, com área de lazer ao longo da mata ciliar do corrégo das Lages até o rio Uberaba;

VIII - criação do Parque Tancredo Neves, preservando as áreas verdes doadas com a implantação do Loteamento Residencial Tancredo Neves e áreas de preservação permanente, com demarcação de espaços para o lazer da população local;

IX - criação de parque no entorno do Piscinão, com áreas de lazer, e em áreas públicas situadas nos córregos que compõem o córrego das Lages;

Além destes, destacam-se nos artigos 108 e 113, a importância de criação de outros parques lineares, como no Córrego Jucá, ao longo do Rio Uberaba (no trecho urbano), e em áreas não definidas nos conjuntos Beija Flor I e II. Contudo, das medidas previstas nos referidos artigos, houveram avanços nos seguintes espaços (como grifados na citação anterior): intervenções parciais nos parques Jacarandá, Mata do Ipê e Córrego das Lages e criação dos parques das Barrigudas (Parque Tecnológico) - não previsto no Plano Diretor -, das Acácias (entorno do Piscinão) e do Paço (Mata José Elias). Estes dois últimos localizam-se em áreas de crescente valorização imobiliária, de claros interesses privados, apesar da importância destes espaços em termos socioambientais.

O Parque das Barrigudas se originou da parceria entre o poder municipal e a Companhia das Águas de Uberaba (CODAU) que o executou como medida de compensação ambiental e o Parque das Acácias resultou parte de um projeto municipal de contenção de águas pluviais (Projeto Água Viva ${ }^{13}$ ), ambos em 2008. Já o Parque do Paço foi implantado em 2011 integrando uma área que agrega vários edifícios públicos do poder judiciário. As demais áreas não sofreram intervenções ou os parques não foram criados, demonstrando o pouco avanço dessas políticas.

No que se refere às medidas para melhorias na infraestrutura dos parques já implantados, notou-se poucos avanços ao longo dos últimos anos. As ações instituídas constituíram-se em paliativas, sem mudanças profundas nas características e arranjo urbanístico e arquitetônico das estruturas dos parques. É comum manterem-se fechados parcial ou totalmente para visitação pública.

As atividades esportivas são na atualidade um dos principais atrativos para os jovens aos parques. A prática do lazer ativo é fundamental para o melhor desempenho da saúde física e mental, auxiliando em processos de sociabilidade, constituindo uma via alternativa, entre outros, na redução da dependência das tecnologias digitais e práticas de sedentarismo. Constitui também uma necessidade, inclusive, para as camadas idosas, possibilitando maior vitalidade. Destarte, a legislação impõe que "a melhoria e ampliação do atendimento à população da rede de serviços e equipamentos voltados para os esportes e o lazer se darão mediante: I - melhoria das praças e espaços de lazer urbano, de acordo com a demanda dos moradores, com instalação de equipamentos para a prática de esporte e lazer; II - [...]" (UBERABA, 2006). Ou seja, a qualidade dos espaços de lazer é assegurada na lei, mas na prática as ações são exíguas.

O Parque Mata do Ipê apresentava-se até poucos anos em estado de abandono, com precárias infraestruturas e pouco trato paisagístico. Medidas previstas no Plano Diretor (art. 109), foram parcialmente executadas, como readequação dos espaços para permitir a visitação, catalogação das espécies vegetais e animais existentes na e criação de uma rota acessível para pessoas com deficiência ou com mobilidade reduzida. Mas, o estado geral do parque ainda é precário, com abertura em horários parciais, caminhos em asfalto, rotas inadequadas, banheiros e bebedouros comprometidos, interdição de pontes e trilhas, ausência de podas etc.

O Parque também pode ser ampliado, pois há terrenos ao entorno que se mostram favoráveis de serem anexados, redundando na proposta de um complexo envolvendo a Fraternidade Betânia, a Secretaria de Saúde e a Unidade da Polícia Civil, possibilitando a criação de pista de caminhadas e corridas, implantação de quadras esportivas, monumentos decorativos, lanchonetes etc. A instalação de equipamentos de ginástica para idosos foi uma medida que favoreceu a atração desse público, embora dada a ausência de atrativos infantis, as crianças usam-na com frequência (Figura 6).

13 O "Projeto Água Viva - Projeto de Recuperação Ambiental da Bacia do Rio Uberaba e Revitalização do Sistema de Abastecimento de Água - teve sua origem e ancora a sua racionalidade na busca de solucionar os mais graves problemas de saneamento ambiental, de controle de cheias e escassez de água do município de Uberaba. O Projeto contempla três vertentes de ações principais: Recuperação ambiental do rio Uberaba, ribeirão Conquistinha e de seus afluentes; Complementação do sistema de esgotamento sanitário; Melhoria do sistema de abastecimento de água". Fonte: PREFEITURA MUNICIPAL DE UBERABA. Projeto Água Viva Relatório Ambiental 1. Codau. s/d. 
Figura 6 - Uberaba (MG): Parque Mata do Ipê (2018).

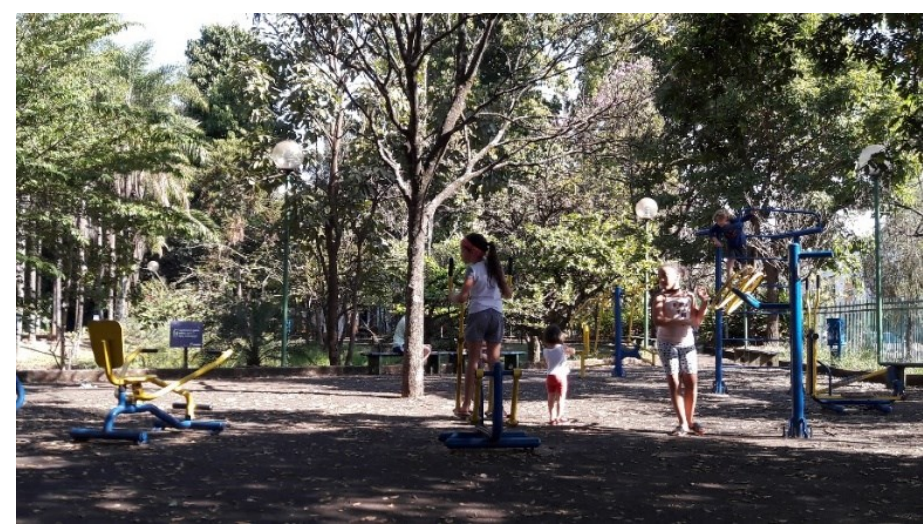

Autor - Marcos Antônio Silvestre Gomes.

No Parque Jacarandá ações foram também desenvolvidas nos últimos anos de modo a melhorar suas condições para usos, embora algumas medidas sejam consideradas inadequadas, como asfaltamento dos caminhos. Apesar da sua importância como área verde e zoológico, este espaço foi cogitado para venda à iniciativa privada face à implantação do Praça Uberaba Shopping (ver figura 4), mas por mobilização popular e de segmentos políticos este fato não sucedeu. Parte de suas instalações encontra-se com problemas e até mesmo em desuso. Apresenta inadequações em relação a muitos equipamentos, sendo precárias as condições dos bebedouros, banheiros, bancos etc. Destaca-se a incompatibilidade das atividades esportivas e de outras formas de lazer ativo visto que abriga um zoológico e o espaço do parque é pequeno, provocando perturbações aos animais.

O Parque Mata do Carrinho permanece fechado para uso público desde 2014. Há em andamento um projeto de requalificação que devolverá este espaço para uso público. No entanto, até o momento as obras, envolto a muitos problemas de gestão, avançaram pouco sem previsão de finalização. Este Parque compõe um complexo ambiental-cultural, agregando o Memorial Chico Xavier, um dos pontos turísticos da cidade. Devido à sua localização em área de médio-baixa renda pode contribuir na ampliação das condições de lazer destas camadas da população.

Como os parques Mata do Ipê e Jacarandá, os parques Mata do Carrinho e das Barrigudas não oferecem estruturas para atividades de lazer ativo. Apresentam-se como locais para práticas contemplativas de observação da natureza, no caso do primeiro, e de descanso ao ar livre, no caso do segundo. No entanto, os Parques do Paço e das Acácias são os mais equipados para estas atividades.

O Parque do Paço constitui um espaço de desenho simples, compondo-se de uma área verde, cercada de gradil, e uma pista que o envolve, onde podem ser praticadas caminhadas, corridas e ciclismo (ver figura 2). Em processo de reforma, houve implantação de bancos, grades externas, academias de ginástica e quadras de esporte e quiosque de alimentação. No entanto, dadas as pretensões imobiliárias para o seu entorno, que mantém muitos terrenos como reservas de valor, o Parque permanece com baixa utilização em vista ao seu potencial, não agregando-se às necessidades dos moradores antigos do entorno que, paulatinamente estão vendendo seus imóveis, devido às ofertas de preços. Como consequência, apartamentos de médio e alto padrão têm surgido no local, ampliando as especulações, substituindo casas populares e expulsando moradores de baixa renda ${ }^{14}$.

Por fim, o Parque das Acácias é o mais completo em termos de infraestrutura e de lazer ativo, constituindo um complexo para atividades esportivas e contemplativas, como lagos, quadras esportivas, pistas de skate, quiosques, pista para caminhada e corrida etc. No entanto, apresenta deficiência quanto à cobertura vegetal, onde muitas árvores ainda encontram-se em estágio inicial de desenvolvimento e mesmo quando atingirem maturidade não serão capazes de proporcionar uma cobertura arbórea adequada no parque de modo que favoreça espaços eficientes de sombra e ampliação de outros benefícios ambientais. Quanto aos seus equipamentos, observa-se uma deterioração gradativa, com pichações frequentes, banheiros e bebedouros em péssimo estado de conservação, quadras esportivas com pouca manutenção etc. Esta condição tem contribuído para o afastamento do público usuário, que não se vê motivado a utilizar o Parque.

${ }^{14}$ Sobre este processo, consultar Ferreira (2015).

$\begin{array}{llllll}\text { Caminhos de Geografia } & \text { Uberlândia-MG } & \text { v. 21, n. } 78 & \text { Dez/2020 } & \text { p. 237-252 } & \text { Página } 247\end{array}$


Até aqui impetrou-se uma análise do quadro geral dos parques efetivamente implantados em Uberaba, demonstrando suas infraestruturas, qualidades e deficiências. Porém, é necessário avançar na compreensão dos espaços previstos para parques, mas que não foram implantados, percebendo suas características e a percepção da população lindeira a estes espaços.

\section{CARACTERIZAÇÃO DOS ESPAÇOS NÃO IMPLANTADOS E A PERCEPÇÃO DA POPULAÇÃO LINDEIRA}

O estudo sobre os parques não implantados em Uberaba demandou observações empíricas e o preenchimento de um formulário para caracterização dos mesmos, bem como entrevistas estruturadas com pessoas lindeiras a estes espaços. O objetivo era entender a situação atual dos parques, sua composição paisagística e em infraestrutura, observando se havia possibilidade de usos pela população. Quatro parques foram visitados nos meses de abril de 2019 e fevereiro de 2020, em horários alternados, sendo eles: Parque Tancredo Neves, Parque Córrego das Lages, Parque Linear Novo Horizonte e Parque São Cristóvão. A escolha se deu por sorteio entre aqueles não implantados.

Como observado no Mapa 1, esses parques encontram-se em localidades distintas, constituem áreas de preservação ambiental, sendo necessário consolidá-los como áreas de lazer para a população e reintegrá-los como áreas verdes à dinâmica urbana. A criação por lei e efetivação destes parques redunda em melhorias das condições de lazer, sobretudo nas periferias pobres, carentes de espaços desta natureza. Por outro lado, resguardaria as condições dos mesmos de patrimônio natural devido a presença de nascentes e inúmeras espécies da flora nativa. Como demonstrou Pegorari (2007), muitos parques em Uberaba, como Mata do Carrinho e Jacarandá, apresentam um importante acervo natural do Cerrado, com rico complexo florístico.

O Parque Tancredo Neves está localizado no bairro Fabrício e não possui nenhum tipo de infraestrutura que a comunidade possa percebê-lo como parque. Nota-se o crescimento desordenado de mato e arbusto, falta de podas e depósito de lixo e entulho no local, em sua maioria proveniente de material de construção (telhas, areia, brita), além de lixos domésticos como embalagens de plástico e papel.

No entorno do Parque predominam edificações residenciais de um pavimento, sendo inexistentes torres de apartamentos. No espaço do parque está localizado um Centro Municipal de Educação Infantil, que poderia aproveitá-lo para processos educativos e agregar usos ao local pela frequência de usuários. O parque tem grande potencial paisagístico e topográfico favorável a um projeto urbanístico, no entanto, nenhuma política pública foi aplicada nesta área (Figura 7).

Figura 7 - Uberaba (MG): Parque Tancredo Neves (2020).

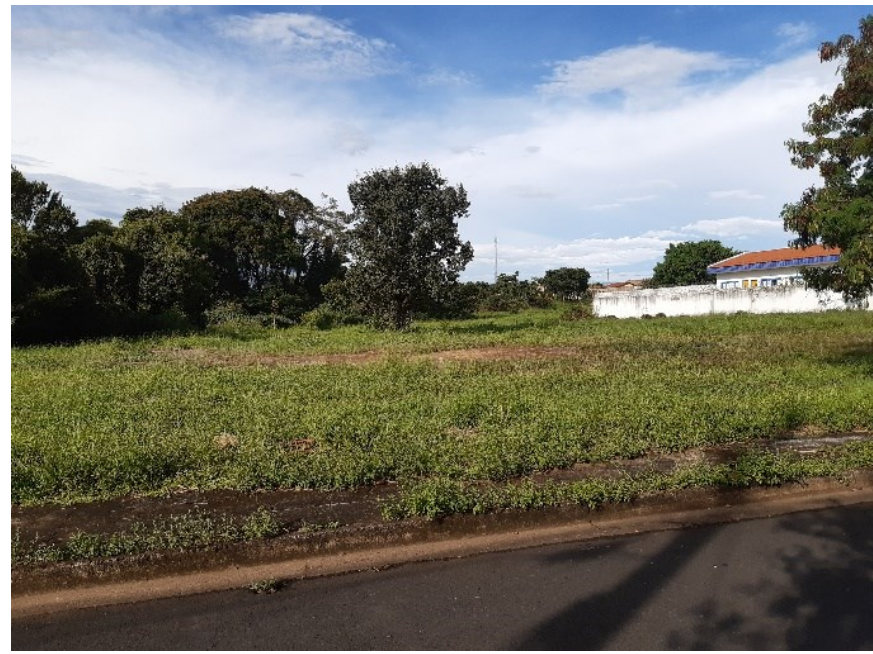

Autor - Marcos Antônio Silvestre Gomes.

O Parque Córrego das Lajes está localizado ao longo da Avenida Leopoldino de Oliveira, no Jardim São Bento. Situa-se em frente ao Praça Uberaba Shopping e ao Terminal Oeste de ônibus, com predominância de edifícios de prédios residenciais e comerciais, que contribui para a intensa

$\begin{array}{lllll}\text { Caminhos de Geografia } & \text { Uberlândia-MG } & \text { v. 21, n. } 78 & \text { Dez/2020 } & \text { p. 237-252 Página } 248\end{array}$


movimentação de carros e pedestres no entorno, mas que não efetivamente usam seu espaço para lazer.

Apesar de ter sido constatada intervenção em sua parte imediata ao Shopping, que favorece usos contemplativos, o espaço em sua totalidade é de precária infraestrutura, já que se estende por centenas de metros linearmente ao Córrego das Lages, com águas fétidas e escuras. Há alguns bancos, lixeiras, iluminação, calçadas e ajardinamento na área em frente ao Shopping, servindo como local de descanso para alguns funcionários. A facilidade de acesso por ônibus e carros torna-o um espaço potencial para receber a devida infraestrutura.

O Parque Linear Grande Horizonte,_localizado em bairro de mesmo nome, compõe a Área de Preservação Permanente (APP) do córrego da Saudade, tornando obrigatória a sua conservação ambiental. Não possui nenhuma sinalização de que é uma APP, sendo comum servir de depósito para diversos tipos de lixo, ou seja, trata-se de um matagal em estado de abandono (Figura 8).

Apesar de o trabalho de campo ter sido realizado durante o dia, entrevistados afirmaram evitar a área, principalmente a noite, já que a falta de iluminação e cercamento ampliam a sensação de insegurança. $\mathrm{O}$ acesso ao Parque é extremamente comprometido, visto que boa parte da sua área é cercada por muros de loteamentos fechados. Este é um problema de muitas APP em Uberaba, que são apropriadas por este tipo de loteamento, impedindo usos democráticos pela população em geral.

Figura 8 - Uberaba (MG): Parque Linear Grande Horizonte (2020).

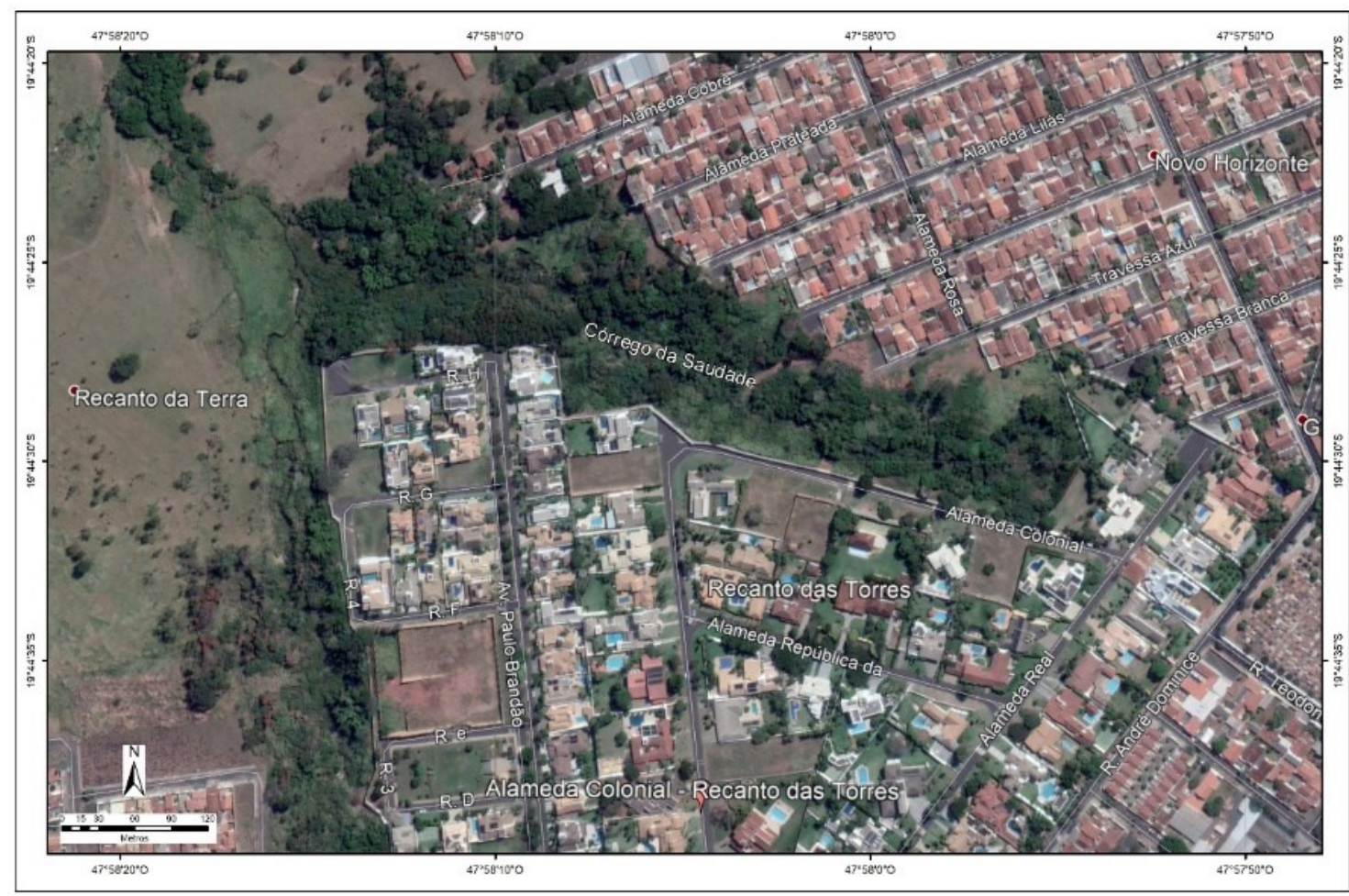

Autor - Marcos Antônio Silvestre Gomes.

O Parque São Cristóvão situa-se ao longo do córrego dos Carneiros. A área ao entorno é predominantemente residencial, não possui infraestrutura que indica ser um parque urbano e, apesar de estar próximo de uma das principais avenidas da cidade, a Leopoldino de Oliveira, tem acessos comprometidos. Encontra-se no lado oposto desta avenida em relação ao Parque Linear Córrego das Lages. Com a poda desordenada e calçamento quebradiço e em falta, o lugar não transmite segurança para quem passa. Em diversos pontos foi encontrado descarte de lixo doméstico. Trata-se de uma parcela do espaço urbano em processo de adensamento com diversos loteamentos e edificações novas.

Com o objetivo de compreender como as pessoas lindeiras percebem o espaço destes parques não

$\begin{array}{lllll}\text { Caminhos de Geografia } & \text { Uberlândia-MG } & \text { v. 21, n. } 78 & \text { Dez/2020 } & \text { p. 237-252 Página } 249\end{array}$


implantados foram entrevistadas 40 transeuntes nas áreas imediatas aos quatro parques, abordando questões relativas às suas percepções e usos efetivos destes espaços.

No geral foram entrevistados $65 \%$ do sexo feminino e $35 \%$ do sexo masculino, compondo-se de indivíduos com idades entre 18 a mais de 60 anos. Mais de $50 \%$ dos entrevistados tinham ensino médio e cerca de $90 \%$ tinham renda familiar entre 1 a 5 salários mínimos.

Quando questionados sobre os parques que conheciam em Uberaba, o Parque das Acácias teve o maior destaque (cerca de $40 \%$ ), seguido da Mata do Ipê e Parque das Barrigudas. Apenas $40 \%$ dos entrevistados costumam frequentar parques e entre aqueles mais destacados estão o Parque das Acácias $(67 \%)$ e o Parque das Barrigudas (27\%). Isto evidencia como a infraestrutura do local é um fator de atração para a comunidade. O primeiro apresenta maior diversidade em opções de lazer ativo e melhor facilidade de acesso, tanto de carro como de transporte público e, o segundo foi consideravelmente lembrado nas respostas, possivelmente pelos frequentes festivais culturais realizados no local, aos domingos.

Quando questionados sobre o conhecimento da área designada parque nas imediações do local da entrevista, $80 \%$ afirmaram conhecer. No entanto, cerca de $90 \%$ relataram nunca a terem utilizado. Todos os entrevistados não sabiam que as áreas estavam previstas como parques no Plano Diretor, $80 \%$ relataram que tinham interesse em fazer uso da mesma caso fosse implantada infraestrutura, em especial para lazer e esporte.

A maioria nunca observou intervenções públicas nas referidas áreas. Entre aqueles que presenciaram, há relatos de podas de árvores e retirada do mato e lixo. Assim, quando questionados sobre a relevância socioambiental de um parque para a referida área, numa escala de 0 a 10 , todas as respostas se enquadraram entre 8 e 10 . Em sua totalidade, afirmaram ainda que da forma que os parques se encontram não contribuem para a valorização dos imóveis ao entorno.

Questionados como definiriam um parque a característica mais lembrada foi a presença da vegetação. Foram termos frequentes: "verde", "natureza" e "árvores", mostrando como a flora permanece entrelaçada com conceito de parque, juntamente com a presença de animais. Outros apontaram o parque urbano como elemento da natureza na cidade. Citaram a presença do verde, mas também elementos de infraestrutura como iluminação, bancos, mesas, além de espaços para caminhadas e para uso recreativo infantil.

Os entrevistados que disseram frequentar parques urbanos souberam elaborar uma resposta de forma mais precisa. Como a maioria dos frequentadores responderam só utilizar o Parque das Acácias, essa foi a referência quando citaram que o parque deve ter espelhos d'água, mesas e bancos para refeições, áreas para esporte, trilhas, além de prover segurança aos usuários, com boa iluminação e guardas.

Foi frisada a importância de ser uma área que sirva a todos, principalmente para programas familiares, tanto para o lazer como para a prática de esportes. A questão da segurança aparece como marcante para os entrevistados onde $60 \%$ pontuaram o uso de cercas e alambrados como uma característica.

Em suma, de maneira geral, muitos entrevistados chegaram a usar expressões como "relaxar na natureza" e "tranquilidade", demonstrando a relação que entendem ter o parque urbano com o descanso, o lazer e o tempo do ócio, necessários aos cidadãos.

\section{CONSIDERAÇÕES FINAIS}

Esta análise destacou aspectos da problemática dos parques urbanos em Uberaba, demonstrando a relação de causa e efeito entre o que está posto na lei e a sua não efetivação, ou mesmo realização parcial. Disto decorre o estado de precariedade da infraestrutura dos parques, o descuido ambiental e o consequente abandono pela população. As leis, integrantes das políticas públicas, se esvaziam em suas proposições à medida que as gestões municipais não as cumprem ou priorizam. É necessário aprimorar o escopo normativo e ampliar o esforço do poder executivo afim de que as medidas de criação e melhoria das condições dos espaços públicos em Uberaba sejam de fato efetivadas. Unificar a gestão dos parques em um único órgão, facilitando a coordenação das ações, e destinar e consolidar um corpo técnico profissional para atuar nestes espaços são medidas fundamentais.

O conjunto da legislação analisada traz a importância de um planejamento urbano voltado para a 
preservação das áreas verdes enquanto espaços de lazer, cultura, socialização e educação. O Plano Diretor Municipal institui os parques como fundamentais pela sua importância ecológica e para a educação ambiental. O Código Municipal do Meio Ambiente reforça a importância da preservação de patrimônios naturais, provendo uma melhoria da qualidade ambiental e garantindo a participação popular e envolvimento da comunidade. Por sua vez, a Lei Orgânica do município destaca a importância dos parques para manifestações culturais, assim como as praças e jardins, sendo "espaços privilegiados para o lazer". Ainda, é fundamental ressaltar que esta lei propõe a criação de parques como um meio de assegurar o direito fundamental ao meio ambiente ecologicamente equilibrado, e, não apenas que os mesmos sejam dotados de "(...) infraestrutura indispensável às suas finalidades".

No entanto, este trabalho constatou que os parques implantados em Uberaba apresentam infraestruturas precárias, intervenções públicas paliativas e incompatíveis com as necessidades destas áreas. Não há propostas de recuperação que possibilitem a reintegração destes espaços à dinâmica urbana. São elaborados projetos sem efetiva participação popular e sem reconhecimento das reais condições e potencialidades destes espaços, a despeito da situação da Mata do Carrinho, cujo projeto de "revitalização" se arrasta por anos, sem previsão de ser concluído. Escassos recursos têm sido aplicados nestes espaços.

Quanto aos parques previstos para serem implantados, estes localizam-se na periferia urbana, constituindo-se em áreas verdes desassistidas pelo poder público e pela população. São visíveis os sinais de desmatamento paulatino do efetivo arbóreo, a degradação proveniente da ausência de podas e qualquer trato paisagístico, depósito de lixos, ausência de estruturas esportivas, medidas de segurança etc. Faz-se necessário a urgente intervenção pública.

Reitera-se aqui a importância dos parques enquanto espaços relevantes na dinâmica socioambiental urbana, que oportunizam múltiplas formas de socialização, recreação, lazer, contato com a natureza, melhoramento estético da paisagem, benefícios ambientais como infiltração das águas, conforto térmico, entre outros. Porém, estas potencialidades podem ser ampliadas por meio da distribuição equilibrada destes espaços na área urbana, privilegiando as diferentes camadas sociais, em especial àquelas mais vulneráveis, de baixa renda e que habitam as periferias pobres, sem acesso a outras formas de lazer do universo mercadológico.

O envolvimento da população nos projetos de parques é fundamental para o seu sucesso enquanto espaço público. A participação popular na elaboração de planos e projetos de parques é prevista no Art. 82 da Lei 375/2007, reiterando os instrumentos de construção e fortalecimento da cidadania, como determina o Estatuto da Cidade (Lei Federal 10.257/2001). Entretanto, a participação efetiva não se verifica, pois não são realizados plebiscitos, reuniões específicas ou consultas populares de caráter formal, ou quando o faz não se realiza de modo satisfatório. O artigo 101 do Plano Diretor destaca entre as diretrizes para o Sistema Ambiental Urbano, o "estímulo à participação comunitária para proteção e recuperação de danos ambientais, inclusive das praças e áreas verdes urbanas". Sem o envolvimento da população em projetos, reformas e qualificação dos espaços dos parques, os usos e sentimentos de pertencimento, entre outros, ficam comprometidos, fato que agrava a situação destes espaços e provoca o afastamento da população.

\section{AGRADECIMENTOS}

À Stella Márcia de Mesquita Pereira, pelas inestimáveis contribuições na pesquisa, sobretudo, nos levantamentos de campo.

\section{REFERÊNCIAS BIBLIOGRÁFICAS}

ANUÁRIO. Anuário Uberaba em dados, 2019 - Realidade, desafios e perspectivas. Editor: Chico Marcos, Setembro de 2019.

BRASIL. Lei $\mathbf{n}^{\circ} \mathbf{1 0 . 2 5 7}$, de 10 de julho de 2001. Regulamenta os artigos 182 e 183 da Constituição Federal, estabelece diretrizes gerais da política urbana e dá outras providências.

CARNEIRO, A. R.; MESQUITA, L. B. Espaços Livres do Recife. Recife: Prefeitura da cidade de Recife/ Universidade Federal de Pernambuco, 2000. 
FERREIRA, L. H. A. O Parque do Paço e a dinâmica da produção e apropriação do espaço urbano em Uberaba-MG. Monografia (Graduação em Geografia). Universidade Federal do Triângulo Mineiro. Uberaba-MG, 2015.

GOMES, M. A. S. Cidades sustentáveis e parques: reflexões teórico-conceituais. Confins, 40, 2019. https://doi.org/10.4000/confins.19428

GOMES, M. A. S; SAVELLI, M. Análise socioespacial das praças públicas de Uberaba-MG. Anais. XVI Simpósio Nacional de Geografia Urbana. Vitória/ES, 2019.

GOMES, M. T. S. Cidades médias, novos espaços produtivos e reestruturação do espaço urbano em Uberaba-MG. Confins, 25, 2015. https://doi.org/10.4000/confins. 10407

GUERRA, Maria Eliza Alves; ROSA, B. P.; GONCALVES, N. Agentes Produtores da Forma Urbana nas Cidades Médias do Triângulo Mineiro. In: Anais. X Colóquio QUAPÁ-SEL, Brasília/DF, 2015.

MACEDO, S. S.; SAKATA, F. G. Parques Urbanos no Brasil. São Paulo: Edusp, 2003.

NASCIMENTO, J. A. Parque Jacarandá em Uberaba-MG: Caracterização e Análise. Monografia (Graduação em Geografia). Universidade Federal do Triângulo Mineiro. Uberaba-MG, 2016.

PEGORARI, P. O. Fitossociologia de três fragmentos florestais urbanos de Uberaba, Minas Gerais. Dissertação (Mestrado em Ecologia e Conservação de Recursos Naturais pela mesma instituição) - Universidade Federal de Uberlândia, Uberlândia, 2007.

SILVA, M. R. Parque Mata do Ipê em Uberaba-MG: Caracterização e Análise. Monografia (Graduação em Geografia). Universidade Federal do Triângulo Mineiro. Uberaba-MG, 2016.

UBERABA. Lei $\mathbf{n}^{\circ} \mathbf{3 8 9}$, de 11 de dezembro de 2008. Institui o Código de Meio Ambiente do Município de Uberaba e dá outras providências.

Lei $\mathbf{n}^{\circ} 359$, de 11 de outubro de 2006. Institui o Plano Diretor do Município de Uberaba e dá outras providências.

Lei $\mathbf{n}^{\circ}$ 376, de 19 de junho de 2007. Dispõe sobre o Uso e Ocupação do Solo no Município de Uberaba, Estado de Minas Gerais, e dá outras providências.

Lei n 65, de $^{\circ} 1$ de março de 1990. Lei Orgânica do Município de Uberaba.

Lei. $\mathbf{n}^{\circ} \mathbf{3 7 5}$, de 18 de junho de 2007. Dispõe sobre o parcelamento do solo urbano e os condomínios urbanísticos no Município de Uberaba.

Recebido em: 22/03/2020

Aceito para publicação em: 29/09/2020 